\title{
Altitude and COPD prevalence: analysis of the PREPOCOL-PLATINO-BOLD-EPI-SCAN study
}

\author{
Andreas Horner ${ }^{1,2,3^{*}}$ D, Joan B. Soriano ${ }^{4}$, Milo A. Puhan ${ }^{5}$, Michael Studnicka ${ }^{6}$, Bernhard Kaiser ${ }^{2}$, \\ Lowie E. G. W. Vanfleteren ${ }^{7,8}$, Louisa Gnatiuc ${ }^{9}$, Peter Burney ${ }^{9}$, Marc Miravitlles ${ }^{10}$, Francisco García-Rio ${ }^{11}$, \\ Julio Ancochea ${ }^{12}$, Ana M. Menezes ${ }^{13}$, Rogelio Perez-Padilla ${ }^{14}$, Maria Montes de Oca ${ }^{15}$, Carlos A. Torres-Duque ${ }^{16,17}$, \\ Andres Caballero ${ }^{17,18}$, Mauricio González-García ${ }^{16}$, Sonia Buist ${ }^{19}$, Maria Flamm³ ${ }^{3}$ Bernd Lamprecht ${ }^{1,2}$, for the BOLD \\ Collaborative Research Group, the EPI-SCAN Team, the PLATINO Team and the PREPOCOL Study Group
}

\begin{abstract}
Background: COPD prevalence is highly variable and geographical altitude has been linked to it, yet with conflicting results. We aimed to investigate this association, considering well known risk factors.

Methods: A pooled analysis of individual data from the PREPOCOL-PLATINO-BOLD-EPI-SCAN studies was used to disentangle the population effect of geographical altitude on COPD prevalence. Post-bronchodilator FEV1/FVC below the lower limit of normal defined airflow limitation consistent with COPD. High altitude was defined as $>1500 \mathrm{~m}$ above sea level. Undiagnosed COPD was considered when participants had airflow limitation but did not report a prior diagnosis of COPD.

Results: Among 30,874 participants aged $56.1 \pm 11.3$ years from 44 sites worldwide, 55.8\% were women, 49.6\% never-smokers, and $12.9 \%$ (3978 subjects) were residing above $1500 \mathrm{~m}$. COPD prevalence was significantly lower in participants living at high altitude with a prevalence of $8.5 \%$ compared to $9.9 \%$, respectively $(p<0.005)$. However, known risk factors were significantly less frequent at high altitude. Hence, in the adjusted multivariate analysis, altitude itself had no significant influence on COPD prevalence. Living at high altitude, however, was associated with a significantly increased risk of undiagnosed COPD. Furthermore, subjects with airflow limitation living at high altitude reported significantly less respiratory symptoms compared to subjects residing at lower altitude.
\end{abstract}

Conclusion: Living at high altitude is not associated with a difference in COPD prevalence after accounting for individual risk factors. However, high altitude itself was associated with an increased risk of undiagnosed COPD.

Keywords: COPD, Geographical altitude, Risk factors, Underdiagnosis, Epidemiology

\section{Background}

COPD is a common condition worldwide, but prevalence estimates are highly variable by time, geography, or other factors beyond age and smoking, which can only partly explain its population variability. Geographical altitude has been linked previously to COPD prevalence, yet with conflicting results [1-9]. First, the PLATINO study found that

\footnotetext{
* Correspondence: Andreas.Horner@kepleruniklinikum.at ${ }^{1}$ Department of Pulmonary Medicine, Kepler University Hospital, Krankenhausstrasse 9, A4021 Linz, Austria

${ }^{2}$ Faculty of Medicine, Johannes-Kepler-University, Linz, Austria

Full list of author information is available at the end of the article
}

the greater the altitude, the lower the prevalence of COPD in five Latin American capitals [1]. In contrast, the PREPOCOL study, conducted in five Colombian cities, reported increasing COPD prevalence with higher altitude [2]. The influence of altitude on other medical conditions has been previously reported. For instance, reports consistently conclude that pulmonary hypertension and right heart failure have a higher prevalence in specific areas at high altitudes $[10,11]$. On the other hand results from the Swiss National Cohort Study indicate that there is lower mortality from coronary heart disease and stroke at higher altitude [12, 13]. Tuberculosis incidence and mortality 
decreases with altitude, whereas mortality for pneumonia and influenza increases with altitude $[14,15]$.

Potential mechanisms behind the assumed impact of altitude on COPD prevalence are highly speculative including that altitude could induce a higher growth of airways relative to lung size, leading to an increased $\mathrm{FEV}_{1} / \mathrm{FVC}$ ratio. This may be an adaptation to external circumstances at high altitude such as chronic hypoxia, the necessary increase in resting ventilation or extreme physical performance, like in Sherpa populations $[4,16]$.

The PREPOCOL-PLATINO-BOLD-EPI-SCAN prevalence and underdiagnosis study was recently published [17]. This study pooled representative samples of adults aged 40 years and older randomly selected from welldefined administrative areas worldwide (44 sites from 27 countries), and has the potential to help to disentangle the population effect of geographical altitude on COPD prevalence. The primary objective of this analysis was to determine the association of COPD prevalence with altitude, taking into account well known COPD risk factors. Secondary objectives were to determine the association of COPD underdiagnosis with altitude and to determine the association of reported symptoms in participants with airflow limitation with altitude.

Some of the results of this study have been previously reported as an abstract [18].

\section{Methods}

\section{Study populations}

The PREPOCOL-PLATINO-BOLD-EPI-SCAN study methods have been described in detail elsewhere [17]. In summary, we used data from 30,874 participants enrolled in the following epidemiologic surveys: (1) BOLD, (2) PLATINO, (3) EPI-SCAN, and (4) PREPOCOL [1, 2, 19, 20].

The BOLD study $[19,21]$ is an ongoing populationbased survey on COPD epidemiology. Field work for the data included was done from 2003 to 2012 and includes data from 16,218 men and women aged $\geq 40$ years in 23 sites. Complete information, including questionnaire data and post-bronchodilator (post-BD) spirometry, were recorded. Details of the study protocol and prevalence of airway obstruction have been reported elsewhere [19, 21].

PLATINO was launched in 2002 in five Latin American cities in five countries. Complete information, including questionnaire data and post-BD spirometry, were recorded for 5315 participants aged $\geq 40$ years [1, 22].

EPI-SCAN was a population-based survey conducted in 11 areas of Spain in 2007. Complete information, including questionnaire data and post-BD spirometry, were recorded for 3802 subjects aged $\geq 40$ years [20,23].

PREPOCOL was an urban population-based study conducted in five Colombian cities in 2003 to 2004. Questionnaire data and post-BD spirometry were recorded for 5539 subjects aged $\geq 40$ years [2].
For all surveys, exclusion criteria were mental illness, institutionalization, inability to conduct spirometry, and contraindications to spirometry or salbutamol.

\section{Study measures}

Post-BD spirometry after two puffs $(200 \mu \mathrm{g})$ of salbutamol was performed in the four included studies. In both BOLD and PLATINO studies, spirometry was done according to American Thoracic Society (ATS) criteria [24] by trained and certified technicians using the ndd EasyOne spirometer (ndd Medical Technologies, Andover, MA, USA and Zurich, Switzerland). EPI-SCAN followed the same guidelines but used the MasterScope CT spirometer (VIASYS Health Care, Hoechberg, Germany). In PREPOCOL, spirometry was performed according to ATS criteria using the MicroLoop spirometer (Micro Medical Ltd., Rochester, Kent, UK). Quality control measures were done according to each study protocol [1, 2, 19-23]. In summary, all interviews and examinations were performed by certified staff, the spirometers were calibrated regularly and the spirometry results were reviewed centrally for quality by a third person. Moreover, regular feedback about the quality of their performance was given to each field worker during the period of data collection and retraining was undertaken as necessary.

\section{Questionnaire}

The questionnaires used for the BOLD study [21], EPISCAN [23], PLATINO [22], and PREPOCOL [2] were administered by trained and certified staff in the participants' native language and included information on respiratory symptoms, respiratory diagnoses, and risk factors for COPD. The questionnaires were translated from English into the study site language and then translated back to ensure accuracy.

\section{Definitions}

COPD was defined by post-BD $\mathrm{FEV}_{1} / \mathrm{FVC}$ below the lower limit of normal (LLN) (persistent airflow limitation) and the Third National Health and Nutrition Examination Survey (NHANES) reference equations [25] were used to calculate predicted values. Ever smoking (current or former smoking) was defined as smoking $>20$ packs of cigarettes in a lifetime or more than one cigarette a day for 1 year. A prior lung function test was defined as present when the question, "Has a doctor or other health-care provider ever had you blow into a machine or device to measure your lungs?" was answered affirmatively. In case of doubt, the interviewers were able to explain the difference between a peak flow meter and a spirometer. A selfreported diagnosis of COPD, emphysema, or chronic bronchitis was based on questionnaire response ("Has a doctor or health-care provider ever told you that you have/had...?"). The reported diagnosis of COPD was 
considered correct if it was accompanied by post-BD airflow limitation $\left(\mathrm{FEV}_{1} / \mathrm{FVC}<\mathrm{LLN}\right)$ at the time of the study visit. Undiagnosed COPD was considered when participants had post-BD $\mathrm{FEV}_{1} / \mathrm{FVC}<\mathrm{LLN}$ but were not given a diagnosis of COPD by a physician or health-care professional. Severity of self-reported dyspnoea was recorded according to the modified Medical Research Council dyspnoea scale (0-4), with dyspnoea defined as present with a score $\geq 1$. Presence of self-reported cough, phlegm, and wheezing was assessed using the following or similar questions: "Do you usually cough when you don't have a cold?"; "Do you usually bring up phlegm from your chest, or do you usually have phlegm in your chest that is difficult to bring up when you don't have a cold?"; "Have you ever had wheezing or whistling in your chest in the last 12 months?".

Occupational exposure to dust or fumes was assessed by questionnaire. Additional measures evaluated included body mass index $\left(\mathrm{kg} / \mathrm{m}^{2}\right)$, total number of years of education, and self-reported physician-diagnosed comorbidities like tuberculosis or heart disease.

High altitude was defined as a geographical altitude of more than $1500 \mathrm{~m}$ above sea level. Although there is no generally acknowledged definition, in literature it is widely accepted as being the cut-off to influence the human body physiology [26-29].

The altitudes of all cities/sites were obtained from the original publications and, if not published, from elevationmap.net (http://www.elevationmap.net) in June 2016.

\section{Statistical analysis}

Data quality was centrally controlled, and a standardized template to translate all coding was applied. Variables were then double-checked by each principal investigator, and data considered as potential errors or outliers were individually discussed, and either confirmed or removed.
Comprehensive tabulations with ranges, means, and SDs of all quantitative variables, and percentages of all qualitative variables were available for each study. All statistics were performed using R-3.3.0 (https://www.r-project.org). Results are expressed as mean \pm SD for quantitative variables and count (percentage) for discrete variables. Parametric t-test, nonparametric Mann-Whitney U test, chi-square tests, and Spearman rank correlation coefficient were used to investigate differences, wherever appropriate. A Weibull model with logarithmic values for altitude was used for the scatterplot in Figs. 1 and 2.

A multivariate logistic regression model was used to examine the association of altitude with COPD prevalence while adjusting for sex, age, body mass index, level of education, smoking status, former tuberculosis, and a history of occupational exposure to dust.

Furthermore, a subgroup analysis in all participants with $\mathrm{FEV}_{1} / \mathrm{FVC}<\mathrm{LLN}$ was performed to evaluate differences in reported symptoms at different altitudes.

In all analyses $p<0.05$ was considered statistically significant.

\section{Results}

Among 30,874 participants aged $56.1 \pm 11.3$ years from 44 sites worldwide, $55.8 \%$ were women, and $49.6 \%$ never-, $27.5 \%$ former- and $22.9 \%$ current-smokers. Overall, $12.9 \%$ or 3978 persons were residing at elevations above $1500 \mathrm{~m}$, while the majority (51.3\%) of the participants was living at altitudes less than $250 \mathrm{~m}$ above sea level. More detailed information on demographics, smoking status, geographical altitude and COPD prevalence by site is presented in Tables 1 and 2 .

As shown in Table 3, COPD prevalence was significantly lower in participants living at high altitude defined as $>1500 \mathrm{~m}$ above sea level, with a prevalence of $8.5 \%$ compared to $9.9 \%$, respectively $(p<0.005)$. As seen in Fig. 1

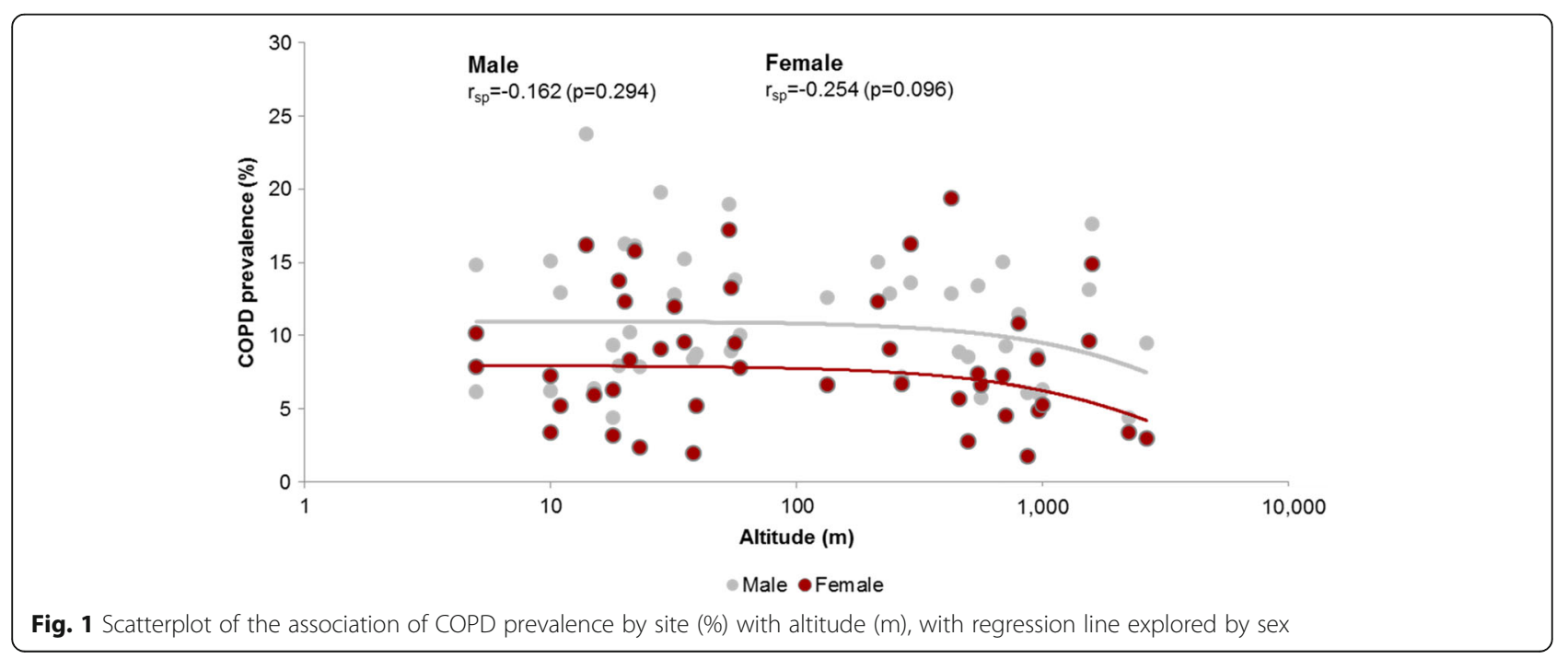




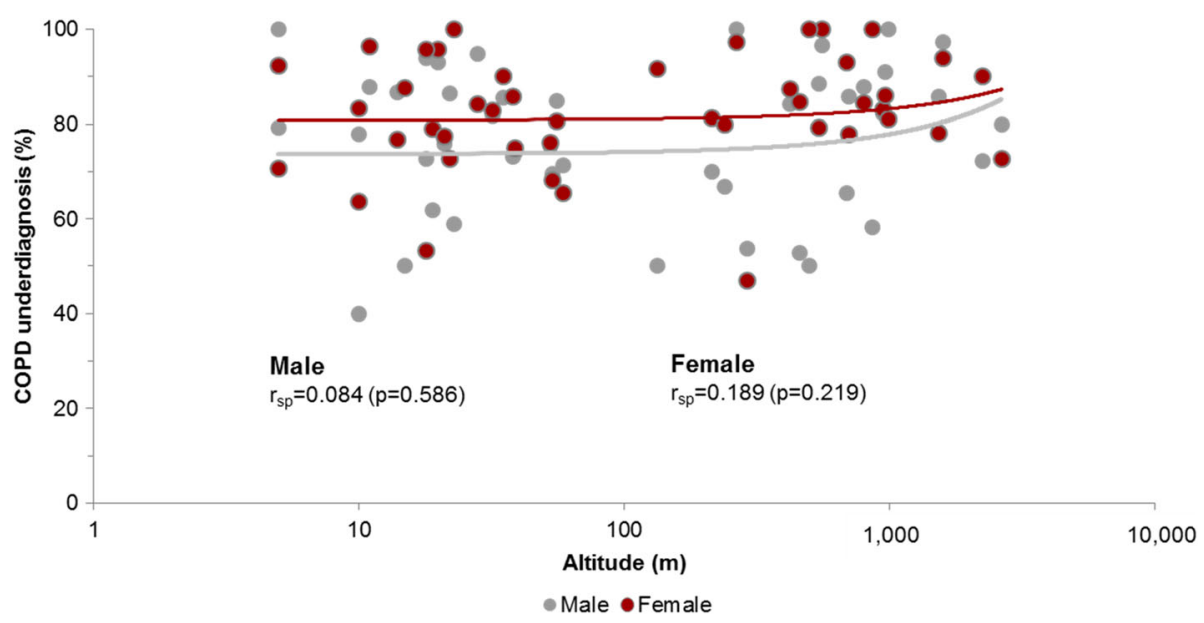

Fig. 2 Scatterplot of the association of COPD underdiagnosis by site (\%) with altitude (m) with regression line explored by sex

this result was consistent for both men and women with Spearman's rank correlation coefficients of -0.162 $(p=0.294)$ and $-0.254(p=0.096)$, respectively. However, risk factors for airflow limitation such as smoking, a history of dusty work environment, or former tuberculosis were significantly less frequent at high altitude. Participants from high altitude were on average significantly younger and reported fewer years of education, see Table 3.

The results of the multivariate analysis adjusted for sex, age, body mass index, level of education, smoking status, and a history of occupational exposure to dust, as plotted in Table 4, do not show any significant association

Table 1 Characteristics of participants

\begin{tabular}{|c|c|c|}
\hline \multicolumn{2}{|l|}{ Characteristics } & \multirow{2}{*}{$\begin{array}{l}\text { Total } n=30,874 \\
17,230(55.8)\end{array}$} \\
\hline Sex, n (\%) & Female & \\
\hline & Male & $13,644(44.2)$ \\
\hline \multirow[t]{4}{*}{ Smoking status, n (\%) } & Never-smoker & $15,308(49.6)$ \\
\hline & Former smoker & $8479(27.5)$ \\
\hline & Current smoker & 7065 (22.9) \\
\hline & Missing information & $22(0.07)$ \\
\hline Age in years, mean $( \pm S D)$ & & $56.1( \pm 11.3)$ \\
\hline \multirow[t]{5}{*}{ Age in decades, $\mathrm{n}(\%)$} & $40-49$ & $10,828(35.1)$ \\
\hline & $50-59$ & $9038(29.3)$ \\
\hline & $60-69$ & $6466(20.9)$ \\
\hline & $70-79$ & $3691(12.0)$ \\
\hline & $\geq 80$ & $851(2.8)$ \\
\hline \multicolumn{2}{|c|}{ Geographical altitude in meters, mean ( \pm SD) } & $521.8( \pm 687.8)$ \\
\hline \multirow[t]{5}{*}{ Geographical altitude, n (\%) } & $0-250$ & $15,823(51.3)$ \\
\hline & $250-500$ & $3437(11.1)$ \\
\hline & $500-750$ & $2737(8.9)$ \\
\hline & $750-1500$ & 4899 (15.9) \\
\hline & $>1500$ & $3978(12.9)$ \\
\hline
\end{tabular}

between living at high altitude (defined as $>1500 \mathrm{~m}$ above sea level) and COPD prevalence.

Interestingly, people with airflow limitation $\left(\mathrm{FEV}_{1} /\right.$ FVC $<$ LLN) living at high altitude are at significantly increased risk of not receiving a diagnosis of COPD (85.8\%) compared to subjects at altitudes <1500 m (80.8\%). This association was seen in both sexes with Spearman's rank correlation coefficients of 0.084 $(p=0.586)$ for males and $0.189(p=0.219)$ for females (Fig. 2).

Only $4.1 \%$ of high altitude residents reported a previous lung function test, and only $3.9 \%$ stated a previous diagnosis of COPD compared to $28.1 \%$ and $5.1 \%$ of subjects living at altitudes $<1500 \mathrm{~m}$, respectively (Table 3 ). These differences were statistically significant. No significant difference was seen in the proportion of correct prior diagnosis of COPD.

Figure 3 illustrates that participants living at high altitude, though having airflow limitation $\left(\mathrm{FEV}_{1} / \mathrm{FVC}<\mathrm{LLN}\right)$, reported significantly less respiratory symptoms like cough, phlegm, dyspnoea or wheeze, compared to subjects residing at lower altitudes.

\section{Discussion}

Our results indicate that living at high altitude is associated with a lower COPD prevalence. However, this could be considered an example of ecological fallacy, and in the multivariate analysis taking into account individual confounders, the association of altitude with COPD prevalence disappeared. Furthermore, living at high altitude was linked to an increased risk of undiagnosed COPD.

In the past, geographical altitude has been linked to COPD prevalence. Until now, the results concerning this topic were inconsistent. In some articles, an association between high altitude and higher COPD prevalence was mentioned, whereas other authors stated a possible protective effect of altitude for COPD. 
Table 2 Altitude and prevalence of COPD (post-BD FEV1/FVC $<L L N$ ) by site and ascending order of altitude

\begin{tabular}{|c|c|c|c|c|}
\hline & Site & Study & Altitude (m) & COPD prevalence (\%) \\
\hline 1 & Bergen, Norway & BOLD & 5 & 12.5 \\
\hline 2 & Mumbai, India & BOLD & 5 & 6.8 \\
\hline 3 & Barcelona, Spain & EPI-SCAN & 10 & 10.7 \\
\hline 4 & Vigo, Spain & EPI-SCAN & 10 & 4.8 \\
\hline 5 & Manila, Philippines & BOLD & 11 & 8.5 \\
\hline 6 & CapeTown, South Africa & BOLD & 14 & 19.0 \\
\hline 7 & Guangzhou, China & BOLD & 18 & 7.8 \\
\hline 8 & Baranquilla, Colombia & Prepocol & 18 & 3.6 \\
\hline 9 & Sydney, Australia & BOLD & 19 & 10.9 \\
\hline 10 & Nampicuan, Philippines & BOLD & 20 & 14.3 \\
\hline 11 & Uppsala, Sweden & BOLD & 21 & 9.3 \\
\hline 12 & London, England & BOLD & 22 & 16.0 \\
\hline 13 & Sevilla, Spain & EPI-SCAN & 23 & 4.9 \\
\hline 14 & Adana, Turkey & BOLD & 28 & 14.3 \\
\hline 15 & Vancouver, Canada & BOLD & 32 & 12.3 \\
\hline 16 & Montevideo, Uruguay & Platino & 35 & 11.9 \\
\hline 17 & Sousse, Tunisia & BOLD & 38 & 5.0 \\
\hline 18 & Tartu, Estonia & BOLD & 39 & 7.0 \\
\hline 19 & Maastricht, Netherlands & BOLD & 53 & 18.2 \\
\hline 20 & Reykjavik, Iceland & BOLD & 54 & 11.0 \\
\hline 21 & Lisbon, Portugal & BOLD & 56 & 11.5 \\
\hline 22 & Hannover, Germany & BOLD & 59 & 8.9 \\
\hline 23 & Cordoba, Spain & EPI-SCAN & 133 & 9.4 \\
\hline 24 & Krakow, Poland & BOLD & 214 & 13.7 \\
\hline 25 & Oviedo, Spain & EPI-SCAN & 239 & 11.0 \\
\hline 26 & Ife, Nigeria & BOLD & 266 & 6.9 \\
\hline 27 & Lexington, USA & BOLD & 291 & 15.2 \\
\hline 28 & Salzburg, Austria & BOLD & 424 & 15.8 \\
\hline 29 & Huesca, Spain & EPI-SCAN & 457 & 7.2 \\
\hline 30 & Vic, Spain & EPI-SCAN & 497 & 5.7 \\
\hline 31 & Santiago, Chile & Platino & 543 & 9.7 \\
\hline 32 & Pune, India & BOLD & 560 & 6.1 \\
\hline 33 & Requena (Valencia), Spain & EPI-SCAN & 588 & 6.2 \\
\hline 34 & Madrid La Princesa, Spain & EPI-SCAN & 648 & 10.9 \\
\hline 35 & Madrid La Paz, Spain & EPI-SCAN & 648 & 6.6 \\
\hline 36 & Sao Paulo, Brazil & Platino & 800 & 11.1 \\
\hline 37 & Burgos, Spain & EPI-SCAN & 864 & 3.9 \\
\hline 38 & Caracas, Venezuela & Platino & 950 & 8.5 \\
\hline 39 & Bucaramanga, Colombia & Prepocol & 960 & 5.3 \\
\hline 40 & Cali, Colombia & Prepocol & 995 & 5.6 \\
\hline 41 & Medellin, Colombia & Prepocol & 1538 & 10.6 \\
\hline 42 & Srinagar, India & BOLD & 1587 & 16.4 \\
\hline 43 & Mexico City, Mexico & Platino & 2240 & 3.8 \\
\hline 44 & Bogotá, Colombia & Prepocol & 2640 & 5.2 \\
\hline
\end{tabular}


Table 3 Demographic characteristics and risk factors for COPD in subjects living at low (<1500 m) and high (>1500 m) altitude

\begin{tabular}{|c|c|c|c|}
\hline Characteristics & $\begin{array}{l}\text { Altitude }<1500 m \\
n=26,896\end{array}$ & $\begin{array}{l}\text { Altitude }>1500 m \\
n=3978\end{array}$ & $p$-value \\
\hline COPD prevalence (\%) & 9.9 & 8.5 & $<0.005$ \\
\hline Mean FEV 1 (Litre, SD) & $2.66(0,85)$ & $2.45(0.78)$ & 0.010 \\
\hline Mean FVC (Litre, SD) & $3.47(1.05)$ & $3.20(0.90)$ & $<0.001$ \\
\hline Mean $\mathrm{FEV}_{1} / \mathrm{FVC}(\mathrm{SD})$ & $76.8(8.8)$ & $76.2(10.0)$ & $<0.001$ \\
\hline Sex - female (\%) & 54.9 & 62.1 & $<0.001$ \\
\hline Age (Mean, SD) & $56.2(11.3)$ & $55.1(11.3)$ & $<0.001$ \\
\hline Never-smoker (\%) & 48.6 & 56.5 & $<0.001$ \\
\hline Dusty job (\%) & 36.1 & 24.5 & $<0.001$ \\
\hline Tuberculosis (\%) ${ }^{\mathrm{a}}$ & 3.5 & 0.4 & $<0.001$ \\
\hline Education >12 years (\%) & 23.6 & 9.5 & $<0.001$ \\
\hline Prior lung function test, ever (\%) & 28.1 & 4.1 & $<0.001$ \\
\hline Self-reported diagnosis of COPD (\%) & 5.1 & 3.9 & $<0.001$ \\
\hline Proportion of correct prior diagnosis of COPD (\%) & 37.0 & 31.2 & 0.158 \\
\hline Proportion of undiagnosed COPD (\%) & 80.8 & 85.8 & 0.029 \\
\hline
\end{tabular}

${ }^{\mathrm{a}} 14,691$ missing values

$b_{5}, 598$ missing values

PLATINO explored the association between altitude and COPD prevalence and reported that the prevalence was lowest in Mexico City (2240 m above sea level) and highest in Montevideo (35 $\mathrm{m}$ above sea level). There was a perfect correlation between the ranks of altitude in the five cities and the COPD prevalence rates (Spearman rank correlation coefficient - 1.0) [1]. It was noted that this finding was consistent with similar reports from the Himalayas $[4,16]$.

The PREPOCOL study reported opposite results [3]. In the general population without airflow limitation both $\mathrm{FVC}$ and $\mathrm{FEV}_{1}$ were significantly higher at higher altitude. However, $\mathrm{FEV}_{1}$ proportionally increased a little more than
FVC, which could increase the $\mathrm{FEV}_{1} / \mathrm{FVC}$ ratio and decrease its ability to define the population with airflow limitation at a higher altitude. A non-significant tendency toward higher COPD prevalence with higher altitude was found, ranging from $6.2 \%$ in Barranquilla (18 m above sea level) to 13.5\% in Medellín (1538 m above sea level) [2].

A recent study conducted in four Peruvian regions reported that COPD prevalence was highest at the highest altitude, with a $R R=1.6$ versus sea level [5], therefore being more consistent with PREPOCOL.

Laniado et al. [6] reported a COPD case-finding study that included 27 Mexican cities, within an altitude range from 1 to $2680 \mathrm{~m}$ above sea level. They described a weak

Table 4 Crude and adjusted odds ratios for COPD (FEV1/FVC $<L L N$ )

\begin{tabular}{|c|c|c|c|c|c|}
\hline Variable & & OR (crude) $(95 \% \mathrm{Cl})$ & $p$-value & OR (multivariate model) $(95 \% \mathrm{Cl})$ & $p$-value \\
\hline \multirow[t]{2}{*}{ Altitude } & $<1500$ & 1 & & 1 & \\
\hline & $>1500$ & $0.85(0.75 ; 0.95)$ & 0.005 & $0.90(0.80 ; 1.02)$ & 0.111 \\
\hline \multirow[t]{2}{*}{ Sex } & Male & 1 & & 1 & \\
\hline & Female & $0.73(0.68 ; 0.79)$ & $<0.001$ & $0.94(0.86 ; 1.02)$ & 0.119 \\
\hline Age in years & & $1.04(1.04 ; 1.04)$ & $<0.001$ & $1.05(1.04 ; 1.05)$ & $<0.001$ \\
\hline \multirow[t]{3}{*}{ Years of education } & $>12$ & 1 & & 1 & \\
\hline & $9-12$ & $1.24(1.11 ; 1.39)$ & $<0.001$ & $1.16(1.03 ; 1.30)$ & 0.015 \\
\hline & $<9$ & $1.48(1.33 ; 1.64)$ & $<0.001$ & $1.24(1.12 ; 1.39)$ & $<0.001$ \\
\hline \multirow[t]{3}{*}{ Smoking status } & Never & 1 & & 1 & \\
\hline & Former & $1.97(1.79 ; 2.16)$ & $<0.001$ & $1.78(1.61 ; 1.97)$ & $<0.001$ \\
\hline & Current & $2.78(2.53 ; 3.05)$ & $<0.001$ & $3.40(3.08 ; 3.76)$ & $<0.001$ \\
\hline Dusty job & & $1.37(1.27 ; 1.48)$ & $<0.001$ & $1.18(1.09 ; 1.29)$ & $<0.001$ \\
\hline
\end{tabular}




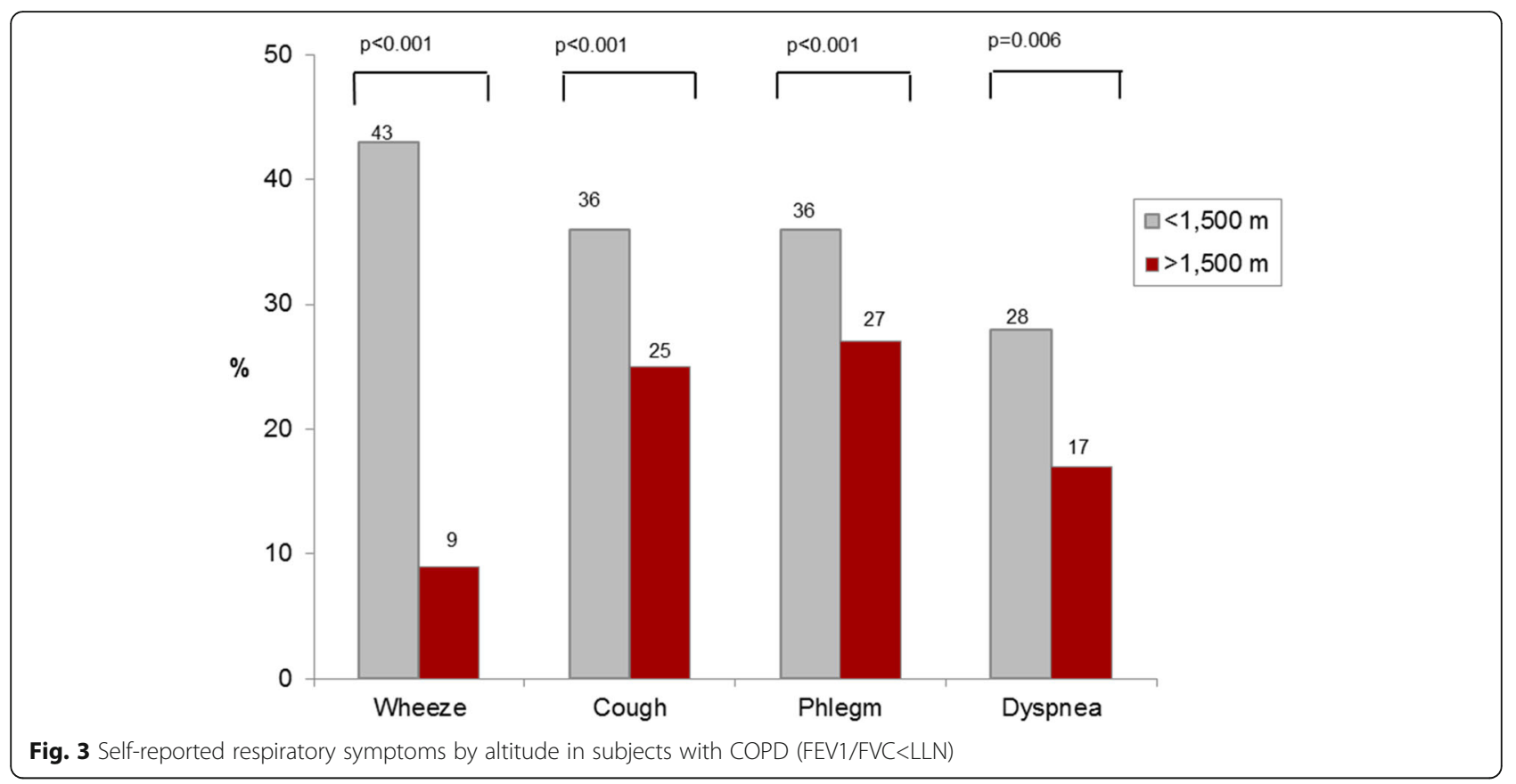

$(-0.31 ; p<0.0001)$ although significant negative correlation between altitude and COPD prevalence. The COPD rate for cities located $\leq 1000 \mathrm{~m}$ was $32.7 \%$ vs $16.4 \%$ for cities located $>1000 \mathrm{~m}(p<0.0001)$; the rate for cities located at $\leq 2000 \mathrm{~m}$ was $22.7 \%$ vs $15.6 \%$ for those $>2000 \mathrm{~m}$.

A recent study by Chan et al. analysed the geographic disparity in mortality rates in Taiwan and found a statistically significant inverse relationship between COPD mortality and altitude [7].

A recent meta-analysis by Aaron et al. of 80 articles published during 2003-2014 found a protective effect of high elevation above sea level for COPD [9]. However, risk factors were only analysed on country-level and not on an individual subject level.

Our study has a number of strengths that help to disentangle these conflicting results. To our knowledge, it is the largest analysis $(n>30,000)$ of the effect of altitude on COPD prevalence with a multinational approach, including various ethnicities and races. Both spirometry and bronchodilator testing were conducted with similar protocols, which likely reduces bias due to methodologic issues. By using the LLN, we avoided problems associated with the use of the fixed ratio of $\mathrm{FEV}_{1} / \mathrm{FVC}$, allowing us to better compare results across studies [30].

A high prevalence of spirometric restriction is likely to occur in low-income countries, and low FVC is likely related to poverty, low birth weight, poor diet, early infections, and exposure to indoor air pollution (burning of biomass fuel) [31-36]. Because local prediction equations may underestimate the local severity, and to be consistent with earlier BOLD publications we deliberately used the
LLN for height, age, and sex on the basis of the Third National Health and Nutrition Examination Survey reference population [25].

COPD mortality is associated with low vital capacity [37]. As the prognostic significance of a given FVC is independent of ethnicity [38], we decided not to adjust the LLN for ethnicity.

High rates of undiagnosed COPD at high altitude may be influenced by the fact that these subjects tend to report significantly less respiratory symptoms. This result is consistent with a previous analysis of our group where COPD underdiagnosis was associated with a lack of reported respiratory symptoms, no previous spirometry and lower education amongst others [17]. However, to reduce underdiagnosis is relevant for COPD patients considering that Çolak et al. reported recently that individuals with undiagnosed symptomatic COPD have an increased risk of exacerbations, pneumonia, and death. Additionally, even individuals with asymptomatic undiagnosed COPD had an increased risk of exacerbations and pneumonia [39, 40].

Furthermore, there is only a poor correlation between reported COPD symptoms and lung function $\left(\mathrm{FEV}_{1}\right)$, and reported symptoms vary in different studies [41]. Hence, other circumstances that come with living at high altitude such as greater poverty, poorer education, lower health literacy, and lack of access to health care resources, may play a role in underdiagnosis of COPD.

Although the proportion of subjects with a previous lung function test is far higher at low altitude, this did not influence the proportion of correct diagnoses of COPD. 
However, some limitations must be noted. All four surveys used different tools and brands of spirometers with somewhat different protocols and quality control. Nevertheless, all spirometers were calibrated and set up to the same ATS/European Respiratory Society guidelines. International variation was also seen across the 23 BOLD sites using the same spirometer (ndd EasyOne), standardized protocol and quality control. Countries assessed are in different stages of the tobacco epidemic, perhaps even by region and other risk factors have a variable distribution, for instance biomass fuel, occupational exposure, educational and poverty levels. However, the PLATINO study has shown that underdiagnosis is as common in subjects with airflow limitation who never smoked as in ever-smokers [42].

Although we adjusted for education as an indicator of socioeconomic status in our multivariate model, there may be other factors that influence COPD prevalence that we were not able to assess. For example, it has been shown, that Hispanic ethnicity is inversely associated with spirometric COPD prevalence even after adjustment for smoking [43]. Occupational exposure to dust was assessed using different questionnaires for workplace exposures in the original studies. Hence, a recall bias may be possible concerning this risk factor.

Some additional determinants of COPD prevalence for example indoor and outdoor air pollution, and biomass exposure [44-46] were not assessed in all the included studies and therefore not analysed. Hence, further research is needed regarding these parameters. Additionally, as a decreasing trend in COPD prevalence in very high altitude cities (> $2000 \mathrm{~m}$ above sea level) was seen, further research in the field of COPD prevalence at very high altitude is desirable.

Although the proportion of missing information concerning most parameters was negligible, there was no data available about former tuberculosis in 14,691 subjects and in 5598 individuals about a prior lung function test. Altitude of all study sites was taken from only one geographic point, the central agglomeration where the study centre was located. These study sites had different catchment areas wherein the altitude of the actual residence of the subjects may vary. However, as the main results of our analysis are based on differences between low and high altitude $(>1500 \mathrm{~m}$ above sea level), minor differences in altitude should not influence the results. The effect of birth place, seasonal traveling and other individual movements, should produce non-differential effects. Unfortunately, we do not have any information if study subjects lived on the same altitude during their whole life or have moved up or down. This may affect disease prevalence as described by Faeh et al. [12] in their Swiss study for coronary heart disease and stroke.

\section{Conclusions}

Living at high altitude is associated with a lower COPD prevalence, but it seems that other related individual risk factors are accountable for this finding. After adjustment for confounders there is no association between high altitude and COPD prevalence. However, high altitude itself is associated with an increased risk of undiagnosed COPD. This may be caused by the fact that individuals at high altitude were less symptomatic despite having an obstructive pattern in their lung function test. Further research is needed to evaluate other risk factors like biomass exposure, indoor and outdoor air pollution, and poverty.

\section{Abbreviations}

ATS: American Thoracic Society; BOLD: Burden of Obstructive Lung Disease; COPD: Chronic Obstructive Pulmonary Disease; EPI-SCAN: Epidemiologic Study of COPD in Spain; LLN: Lower limit of normal; NHANES: Third National Health and Nutrition Examination Survey; PLATINO: The Latin American Project of the Investigation of Obstructive Lung Diesease; post-BD: Post-bronchodilator; PREPOCOL: Prevalence Study of COPD in Colombia

\section{Acknowledgements}

We would like to thank Petra Lichtenberger (Department of Pulmonary Medicine, Kepler University Hospital, Linz, Austria) for her assistance in designing the figures.

\section{Funding}

The initial BOLD (Burden of Obstructive Lung Disease) program was funded in part by unrestricted educational grants to the coordinating Centre in Portland, USA from Aventis, AstraZeneca, Boehringer-Ingelheim, Chiesi, GlaxoSmithKline, Merck, Novartis, Pfizer, Schering-Plough, Sepracor and University of Kentucky. The BOLD Study is currently funded by a grant from The Wellcome Trust (085790/Z/08/Z), which supports the London, UK Co-ordinating Centre.

Additional local support for BOLD sites was provided by: Boehringer Ingelheim China (GuangZhou, China); Turkish Thoracic Society, Boehringer-Ingelheim, and Pfizer (Adana, Turkey); Altana, Astra-Zeneca, Boehringer-Ingelheim, GlaxoSmithKline, Merck Sharpe \& Dohme, Novartis, Salzburger Gebietskrankenkasse and Salzburg Local Government (Salzburg, Austria); Research for International Tobacco Control, the International Development Research Centre, the South African Medical Research Council, the South African Thoracic Society GlaxoSmithKline Pulmonary Research Fellowship, and the University of Cape Town Lung Institute (Cape Town, South Africa); Landspitali-University Hospital-Scientific Fund, GlaxoSmithKline Iceland, and AstraZeneca Iceland (Reykjavik, Iceland); GlaxoSmithKline Pharmaceuticals, Polpharma, Ivax Pharma Poland, AstraZeneca Pharma Poland, ZF Altana Pharma, Pliva Kraków, Adamed, Novartis Poland, Linde Gaz Polska, Lek Polska, Tarchomińskie Zakłady Farmaceutyczne Polfa, Starostwo Proszowice, Skanska, Zasada, Agencja Mienia Wojskowego w Krakowie, Telekomunikacja Polska, Biernacki, Biogran, Amplus Bucki, Skrzydlewski, Sotwin, and Agroplon (Krakow, Poland); Boehringer-Ingelheim, and Pfizer Germany (Hannover, Germany); the Norwegian Ministry of Health's Foundation for Clinical Research, and Haukeland University Hospital's Medical Research Foundation for Thoracic Medicine (Bergen, Norway); AstraZeneca, Boehringer-Ingelheim, Pfizer, and GlaxoSmithKline (Vancouver, Canada); Marty Driesler Cancer Project (Lexington, Kentucky, USA); Altana, Boehringer Ingelheim (Phil), GlaxoSmithKline, Pfizer, Philippine College of Chest Physicians, Philippine College of Physicians, and United Laboratories (Phil) (Manila, Philippines); Air Liquide Healthcare P/L, AstraZeneca P/L, Boehringer Ingelheim P/L, GlaxoSmithKline Australia P/L, Pfizer Australia P/L (Sydney, Australia), Department of Health Policy Research

Programme, Clement Clarke International (London, United Kingdom); Boehringer Ingelheim and Pfizer (Lisbon, Portugal); Swedish Heart and Lung Foundation, The Swedish Association against Heart and Lung Diseases, Glaxo Smith Kline (Uppsala, Sweden); GlaxoSmithKline, Astra Zeneca, Eesti Teadusfond (Estonian Science Foundation) (Tartu, Estonia); AstraZeneca, CIRO HORN (Maastricht, The Netherlands); Sher-i-Kashmir Institute of Medical Sciences, Srinagar, J\&K (Srinagar, India); Foundation for Environmental Medicine, Kasturba Hospital, Volkart Foundation 
(Mumbai, India); Boehringer Ingelheim (Sousse, Tunisia); Philippines College of Physicians, Philippines College of Chest Physicians, AstraZeneca, Boehringer Ingelheim, GlaxoSmithKline, Orient Euro Pharma, Otsuka Pharma, United Laboratories Phillipines (Nampicuan, Philippines); National Heart and Lung Institute, Imperial College, London (Pune, India); The Wellcome Trust, National Population Commission, Ile-lfe, Osun State, Nigeria (lle-lfe, Nigeria).

The Latin American Project for the Investigation of Obstructive Lung Disease (PLATINO) was funded by Boehringer Ingelheim $\mathrm{GmbH}$.

The Epidemiologic Study of COPD in Spain (EPI-SCAN) study was funded by an unrestricted grant from GlaxoSmithKline Spain.

The Prevalence Study of COPD in Colombia (PREPOCOL) was sponsored by an educational contribution from the Colombian offices of Boehringer Ingelheim $\mathrm{GmbH}$ and Pfizer Inc. (Bogotá, Colombia).

Apart from the financial support for the original studies mentioned above, no further funding was provided for the current work.

The sponsors of the different and pooled epidemiological studies played no role in the study design, data collection, data analysis, data interpretation, or writing of the report. The corresponding author had full access to all the data in the study and had final responsibility for the decision to submit for publication.

\section{Availability of data and materials}

The datasets used and analysed during the current study are available from the corresponding author on reasonable request.

\section{Authors' contributions}

$\mathrm{AH}$ had full access to all the data in the study and takes responsibility for the integrity of the data and the accuracy of the data analysis, including and especially any adverse events. AH, BL, JBS, and BK contributed to the study conception and design, data analysis and interpretation, and final approval of the manuscript. $A H, B L$ and JBS contributed to drafting the manuscript. MAP, MS, LEV, LG, PB, MM, FG-R, JA, AMM, RP-P, MMdO, CAT-D, AC, MG-G, $\mathrm{SB}$, and MF contributed to the data interpretation, critical revision of the manuscript for important intellectual content, and final approval of the manuscript. All authors read and approved the final manuscript.

\section{Ethics approval and consent to participate}

All participants provided written informed consent to participate in the studies. In the BOLD and PLATINO studies, all institutions involved obtained approval from its local ethical committee. The protocol of the PREPOCOL study was approved by the Ethics Research Committee of the Fundación Neumológica Colombiana and the Colombian Drug and Food Surveillance Institute. The EPI-SCAN study was approved by the Ethics Committee of the Hospital Clinic de Barcelona, as a reference IRB and consequently by the local Ethics Committees of the participating centres.

\section{Consent for publication}

Not applicable.

\section{Competing interests}

A. H., J. B. S., M. A. P., M. S., B. K., L. E. V., L. G., P. B., F. G.-R., J. A., R. P.-P., M. M. d. O., C. A. T.-D., A. C., M. G.-G., S. B., M. F., and B. L. have nothing to disclose. M. M. reports personal fees from Almirall, Boehringer Ingelheim, AstraZeneca, Chiesi, GlaxoSmithKline, Menarini, Teva, Grifols, Bayer Schering, Gebro Pharma, CLS Behring, Cipla, Medilmmune, Takeda, and Novartis outside the submitted work.

A. M. M. reports personal fees from GSK and Astra Zeneca outside the submitted work.

\section{Publisher's Note}

Springer Nature remains neutral with regard to jurisdictional claims in published maps and institutional affiliations.

\section{Author details}

${ }^{1}$ Department of Pulmonary Medicine, Kepler University Hospital, Krankenhausstrasse 9, A4021 Linz, Austria. ${ }^{2}$ Faculty of Medicine, Johannes-Kepler-University, Linz, Austria. ${ }^{3}$ Institute of General Practice, Family Medicine and Preventive Medicine, Paracelsus Medical University, Salzburg, Austria. ${ }^{4}$ Instituto de Investigación Hospital Universitario de la Princesa (IISP), Universidad Autónoma de Madrid, Madrid, Spain. ${ }^{5}$ Epidemiology, Biostatistics and Prevention Institute, University of Zurich, Zurich, Switzerland.
${ }^{6}$ Department of Pulmonary Medicine, Paracelsus Medical University, Salzburg, Austria. ${ }^{7}$ Department of Respiratory Medicine, Maastricht University Medical Centre, Maastricht, The Netherlands. ${ }^{8}$ Program Development Centre, CIRO+, Centre of Expertise for Chronic Organ Failure, Horn, The Netherlands. ${ }^{9}$ Respiratory Epidemiology and Public Health, Imperial College, London, UK. ${ }^{10}$ Servicio de Neumología, Hospital Universitari Vall d'Hebron. Ciber de Enfermedades Respiratorias (CIBERES), Barcelona, Spain. ${ }^{11}$ Servicio de Neumología, Hospital Universitario La Paz, IdiPAZ. Ciber de Enfermedades Respiratorias (CIBERES), Madrid, Spain. ${ }^{12}$ Servicio de Neumología, Hospital La Princesa, Universidad Autónoma de Madrid, Madrid, Spain. ${ }^{13}$ Programa de Pós-Graduacão em Epidemiologia, Universidade Federal de Pelotas, Pelotas, Brazil. ${ }^{14}$ Institute of Respiratory Diseases, Instituto Nacional de Enfermedades Respiratorias, Mexico City, Mexico. ${ }^{15}$ Servicio de Neumonología, Hospital Universitario de Caracas, Facultad de Medicina, Universidad Central de Venezuela, Caracas, Venezuela. ${ }^{16}$ Departamento de Investigación, Fundación Neumológica Colombiana, Bogotá, Colombia. ${ }^{17}$ Asociación Colombiana de Neumología y Cirugía de Tórax, Bogotá, Colombia. ${ }^{18}$ Clínica Reina Sofía, Bogotá, Colombia. ${ }^{19}$ Oregon Health and Science University, Portland, Oregon, USA.

Received: 8 May 2017 Accepted: 13 August 2017

Published online: 23 August 2017

\section{References}

1. Menezes AM, Perez-Padilla R, Jardim JR, Muino A, Lopez MV, Valdivia G, Montes de Oca M, Talamo C, Hallal PC, Victora CG, Team P. Chronic obstructive pulmonary disease in five Latin American cities (the PLATINO study): a prevalence study. Lancet. 2005;366:1875-81.

2. Caballero A, Torres-Duque CA, Jaramillo C, Bolivar F, Sanabria F, Osorio P, Orduz C, Guevara DP, Maldonado D. Prevalence of COPD in five Colombian cities situated at low, medium, and high altitude (PREPOCOL study). Chest. 2008;133:343-9.

3. Maldonado D, Caballero A, Torres Duque C, Jaramillo C. Diferencias de la capacidad vital forzada según la altitud en Colombia (Differences of the forced vital capacity according to altitude in Colombia) [in Spanish]. 2004; 40(suppl 4):22-3. Arch Bronconeumol. 2004;40(suppl 4):22-3.

4. Havryk AP, Gilbert M, Burgess KR. Spirometry values in Himalayan high altitude residents (Sherpas). Respir Physiol Neurobiol. 2002;132:223-32.

5. Jaganath D, Miranda JJ, Gilman RH, Wise RA, Diette GB, Miele CH, Bernabe-Ortiz A, Checkley W, Group CCS. Prevalence of chronic obstructive pulmonary disease and variation in risk factors across four geographically diverse resource-limited settings in Peru. Respir Res. 2015;16:40.

6. Laniado-Laborin R, Rendon A, Batiz F, Alcantar-Schramm JM, Bauerle O. High altitude and chronic obstructive pulmonary disease prevalence: a casual or causal correlation? Arch Bronconeumol. 2012;48:156-60.

7. Chan TC, Chiang PH, Su MD, Wang HW, Liu MS. Geographic disparity in chronic obstructive pulmonary disease (COPD) mortality rates among the Taiwan population. PLoS One. 2014;9:e98170.

8. Ezzati M, Horwitz ME, Thomas DS, Friedman AB, Roach R, Clark T, Murray CJ, Honigman B. Altitude, life expectancy and mortality from ischaemic heart disease, stroke, COPD and cancers: national population-based analysis of US counties. J Epidemiol Community Health. 2012;66:e17.

9. Aaron SD, Gershon AS, Gao Y, Yang J, Whitmore GA. Influence of countrylevel differences on COPD prevalence. Int J Chron Obstruct Pulmon Dis. 2016;11:2305-13.

10. Penaloza D, Arias-Stella J. The heart and pulmonary circulation at high altitudes: healthy highlanders and chronic mountain sickness. Circulation. 2007;115:1132-46.

11. Mirrakhimov AE, Strohl KP. High-altitude pulmonary hypertension: an update on disease pathogenesis and management. Open Cardiovasc Med J. 2016;10:19-27.

12. Faeh D, Gutzwiller F, Bopp M, Swiss National Cohort Study G. Lower mortality from coronary heart disease and stroke at higher altitudes in Switzerland. Circulation. 2009;120:495-501.

13. Faeh D, Moser A, Panczak R, Bopp M, Roosli M, Spoerri A, Swiss National Cohort Study G. Independent at heart: persistent association of altitude with ischaemic heart disease mortality after consideration of climate, topography and built environment. J Epidemiol Community Health. 2016; 70:798-806. 
14. Perez-Padilla R, Franco-Marina F. The impact of altitude on mortality from tuberculosis and pneumonia. Int J Tuberc Lung Dis. 2004;8:1315-20.

15. Mansoer JR, Kibuga DK, Borgdorff MW. Altitude: a determinant for tuberculosis in Kenya? Int J Tuberc Lung Dis. 1999;3:156-61.

16. Wood S, Norboo T, Lilly M, Yoneda K, Eldridge M. Cardiopulmonary function in high altitude residents of Ladakh. High Alt Med Biol. 2003:4:445-54.

17. Lamprecht B, Soriano JB, Studnicka M, Kaiser B, Vanfleteren LE, Gnatiuc L, Burney P, Miravitlles M, Garcia-Rio F, Akbari K, et al. Determinants of underdiagnosis of COPD in national and international surveys. Chest. 2015; 148:971-85.

18. Horner A, et al. Poster 40: Altitude and COPD prevalence and other determinants: analysis of the PREPOCOL-PLATINO-BOLD-EPISCAN study, 40th Jahrestagung der Österreichischen Gesellschaft für Pneumologie. Wien, 6.-8. Oktober 2016. Wien Klin Wochenschr. 2016;128:751-84.

19. Buist AS, McBurnie MA, Vollmer WM, Gillespie S, Burney P, Mannino DM, Menezes AM, Sullivan SD, Lee TA, Weiss KB, et al. International variation in the prevalence of COPD (the BOLD study): a population-based prevalence study. Lancet. 2007;370:741-50.

20. Miravitlles M, Soriano JB, Garcia-Rio F, Munoz L, Duran-Tauleria E, Sanchez G, Sobradillo V, Ancochea J. Prevalence of COPD in Spain: impact of undiagnosed COPD on quality of life and daily life activities. Thorax. 2009; 64:863-8.

21. Buist AS, Vollmer WM, Sullivan SD, Weiss KB, Lee TA, Menezes AM, Crapo $R O$, Jensen RL, Burney PG. The Burden of Obstructive Lung Disease Initiative (BOLD): rationale and design. COPD. 2005;2:277-83.

22. Menezes AM, Victora CG, Perez-Padilla R, Team P. The Platino project: methodology of a multicenter prevalence survey of chronic obstructive pulmonary disease in major Latin American cities. BMC Med Res Methodol. 2004:4:15.

23. Ancochea J, Badiola C, Duran-Tauleria E, Garcia Rio F, Miravitlles M, Munoz L, Sobradillo V, Soriano JB. The EPI-SCAN survey to assess the prevalence of chronic obstructive pulmonary disease in Spanish 40-to-80-year-olds: protocol summary. Arch Bronconeumol. 2009:45:41-7.

24. Standardization of Spirometry, 1994 update. American Thoracic Society. Am J Respir Crit Care Med. 1995;152:1107-36.

25. Hankinson JL, Odencrantz JR, Fedan KB. Spirometric reference values from a sample of the general U.S. population. Am J Respir Crit Care Med. 1999;159: $179-87$.

26. Taylor AT. High-altitude illnesses: physiology, risk factors, prevention, and treatment. Rambam Maimonides Med J. 2011:2:e0022.

27. Burtscher M. Effects of living at higher altitudes on mortality: a narrative review. Aging Dis. 2014;5:274-80

28. Schommer K, Bartsch P. Basic medical advice for travelers to high altitudes. Dtsch Arztebl Int. 2011;108:839-47. quiz 848

29. Gallagher SA, Hackett PH. High-altitude illness. Emerg Med Clin North Am. 2004;22:329-55. viii

30. van Dijk WD, Gupta N, Tan WC, Bourbeau J. Clinical relevance of diagnosing COPD by fixed ratio or lower limit of normal: a systematic review. COPD. 2014;11:113-20

31. Hancox RJ, Poulton R, Greene JM, McLachlan CR, Pearce MS, Sears MR. Associations between birth weight, early childhood weight gain and adult lung function. Thorax. 2009;64:228-32.

32. Stein CE, Kumaran K, Fall CH, Shaheen SO, Osmond C, Barker DJ. Relation of fetal growth to adult lung function in south India. Thorax. 1997;52:895-9.

33. Canoy D, Pekkanen J, Elliott P, Pouta A, Laitinen J, Hartikainen AL, Zitting P, Patel S, Little MP, Jarvelin MR. Early growth and adult respiratory function in men and women followed from the fetal period to adulthood. Thorax. 2007;62:396-402

34. Misra P, Srivastava R, Krishnan A, Sreenivaas V, Pandav CS. Indoor air pollution-related acute lower respiratory infections and low birthweight: a systematic review. J Trop Pediatr. 2012;58:457-66.

35. Shaheen SO, Barker DJ, Holgate ST. Do lower respiratory tract infections in early childhood cause chronic obstructive pulmonary disease? Am J Respir Crit Care Med. 1995;151:1649-51. discussion 1651-1642

36. Kulkarni N, Pierse N, Rushton L, Grigg J. Carbon in airway macrophages and lung function in children. N Engl J Med. 2006;355:21-30.

37. Burney $P$, Jithoo A, Kato B, Janson C, Mannino D, Nizankowska-Mogilnicka $E$, Studnicka M, Tan W, Bateman E, Kocabas A, et al. Chronic obstructive pulmonary disease mortality and prevalence: the associations with smoking and poverty-a BOLD analysis. Thorax. 2014;69:465-73.
38. Burney PG, Hooper RL. The use of ethnically specific norms for ventilatory function in African-American and white populations. Int J Epidemiol. 2012 41:782-90.

39. Colak Y, Afzal S, Nordestgaard BG, Vestbo J, Lange P. Prognosis of asymptomatic and symptomatic, undiagnosed COPD in the general population in Denmark: a prospective cohort study. Lancet Respir Med. 2017:5:426-34.

40. Almagro P, Soriano JB. Underdiagnosis in COPD: a battle worth fighting. Lancet Respir Med. 2017;5:367-8.

41. Miravitlles M, Ribera A. Understanding the impact of symptoms on the burden of COPD. Respir Res. 2017;18:67.

42. Perez-Padilla R, Fernandez R, Lopez Varela MV, Montes de Oca M, Muino A, Talamo C, Brito Jardim JR, Valdivia G, Baptista Menezes AM. Airflow obstruction in never smokers in five Latin American cities: the PLATINO study. Arch Med Res. 2012;43:159-65.

43. Bruse S, Sood A, Petersen H, Liu Y, Leng S, Celedon JC, Gilliland F, Celli B, Belinsky SA, Tesfaigzi Y. New Mexican Hispanic smokers have lower odds of chronic obstructive pulmonary disease and less decline in lung function than non-Hispanic whites. Am J Respir Crit Care Med. 2011;184:1254-60.

44. van Gemert F, Kirenga B, Chavannes N, Kamya M, Luzige S, Musinguzi P, Turyagaruka J, Jones R, Tsiligianni I, Williams S, et al. Prevalence of chronic obstructive pulmonary disease and associated risk factors in Uganda (FRESH AIR Uganda): a prospective cross-sectional observational study. Lancet Glob Health. 2015;3:e44-51.

45. Kurmi OP, Lam KB, Ayres JG. Indoor air pollution and the lung in low- and medium-income countries. Eur Respir J. 2012:40:239-54.

46. Edited by Annesi-Maesano I, Lundbäck B, Viegi G. Respiratory Epidemiology: European Respiratory Monograph 65. 2014. doi:10.1183/2312508X.erm6514.

\section{Submit your next manuscript to BioMed Central and we will help you at every step:}

- We accept pre-submission inquiries

- Our selector tool helps you to find the most relevant journal

- We provide round the clock customer support

- Convenient online submission

- Thorough peer review

- Inclusion in PubMed and all major indexing services

- Maximum visibility for your research

Submit your manuscript at www.biomedcentral.com/submit

) Biomed Central 